\title{
South East
}

\section{South East population density: by local or unitary authority, 2009}

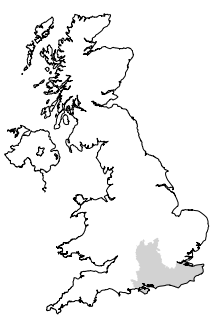

Population density, 2009 (people per sq $\mathrm{km}$ )

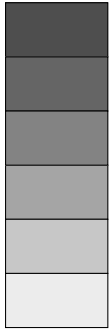

2,500 or over

$1,000-2,499$

$500-999$

$250-499$

$100-249$

99 or under

1 Milton Keynes UA 14 Epsom and Ewell

2 Oxford

3 South Bucks

4 Windsor and

Maidenhead UA

5 Slough UA

6 Reading UA

7 Wokingham UA

8 Bracknell Forest

UA

9 Runnymede

10 Spelthorne

11 Surrey Heath

12 Woking

13 Elmbridge

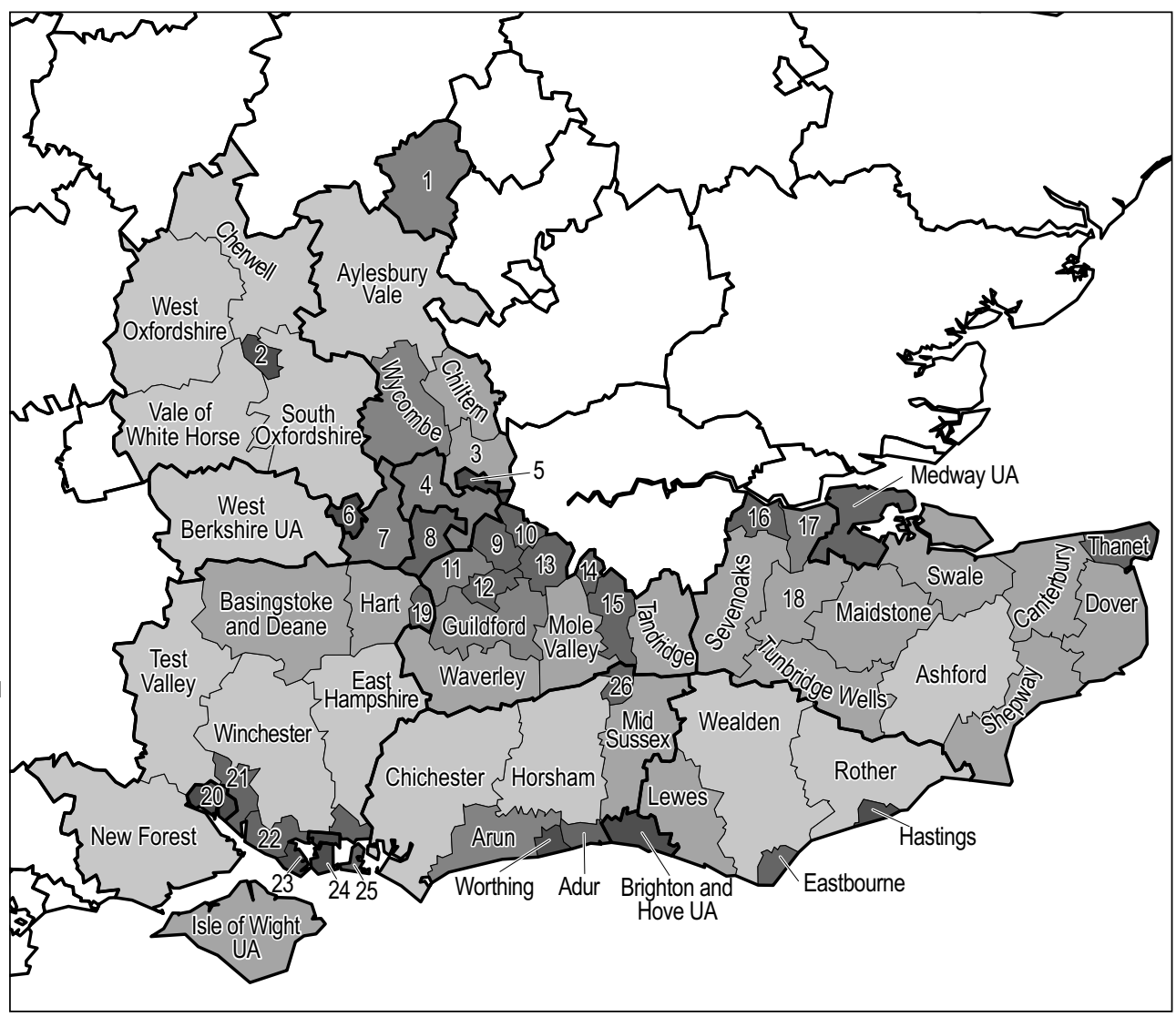

Contains Ordnance Survey data @ Crown copyright and database right 2011

- The South East had a population of 8.4 million in mid-2009, an increase of 4.0 per cent since 2004. This compares with an overall increase of 3.3 per cent for the UK over the same period. (Table 1.2)

- People aged 65 and over in the South East in 2009 made up 17.0 per cent of the population, compared with 18.9 per cent for the under-16s. This compares with averages for the UK of 16.4 per cent and 18.7 per cent respectively. (Table 10.2)

- In the South East men aged 65 in 2007-09 could expect to live another 18.7 years and women 21.3 years. This compares with 17.8 and 20.4 years in the UK as a whole. (Table 6.8)

- The unemployment rate in the South East stood at 6.1 per cent in the fourth quarter of 2010, lower than the UK rate of 7.9 per cent. (Table 1.1)

- A lower proportion of children in the South East (9.5 per cent) lived in workless households in the second quarter of 2010 than the England average (15.9 per cent). (Table 8.6)

- In April 2010, the median gross weekly earnings for full-time employees on adult rates who were resident in the South East was $£ 548$, higher than the UK median of $£ 499$. (Table 9.19)

- $\quad$ Labour productivity (gross value added per hour worked) in the South East in 2009 was 4.1 per cent above the UK average. (Table 3.2)

- In the South East, 53.7 per cent of pupils achieved five or more grades $A^{*}-C$ at GCSE level or equivalent including English and mathematics in 2008/09, compared with 49.8 per cent for England as a whole. (Table 4.8)

- Local authorities in the South East recycled or composted 40 per cent of household waste in 2009/10, equal to the England average. (Table 5.11) 